\title{
A novel method for determining fixed running time in operating electric train tracking optimal speed profile
}

\author{
An Thi Hoai Thu Anh ${ }^{1}$, Nguyen Van Quyen ${ }^{2}$ \\ ${ }^{1}$ Department of Electrical Engineering, University of Transport and Communications, Vietnam \\ ${ }^{2}$ Department of Applied Mechanics, Hanoi University of Science and Technology, Vietnam
}

\begin{tabular}{l} 
Article Info \\
\hline Article history: \\
Received Jan 15, 2021 \\
Revised Apr 15, 2021 \\
Accepted May 12, 2021 \\
\hline Keywords: \\
Energy-saving \\
Metro system \\
Pontryagin's maximum \\
principle \\
Timetable optimization
\end{tabular}

\section{Article Info}

Article history

Received Jan 15, 2021

Revised Apr 15, 2021

Timetable optimization

\begin{abstract}
Tracking the optimal speed profile in electric train operation has been proposed as a potential solution for reducing energy consumption in electric train operation, at no cost to improve infrastructure of existing Metro lines as well. However, the optimal speed profile needs to meet fixed running time. Therefore, this paper focuses on a new method for determining the fixed running time complied with the scheduled timetable when trains track the optimal speed profile. The novel method to ensure the fixed running time is the numerical-analytical one. Calculating accelerating time ta, coasting time $\mathrm{tc}$, braking time tb via values of holding speed $\mathrm{vh}$, braking speed $\mathrm{vb}$ of optimal speed profile with the constraint condition: the running time equal to the demand time. The other hands, vh and $\mathrm{vb}$ are determined by solving nonlinear equations with constraint conditions. Additionally, changing running time suit for each operation stage of metro lines or lines starting to conduct schedules by the numerical-analytical method is quite easy. Simulation results obtained for two scenarios with data collected from electrified trains of Cat Linh-Ha Dong metro line, Vietnam show that running time complied with scheduled timetables, energy saving by tracking optimal speed profile for the entire route is up to $8.7 \%$, if the running time is one second longer than original time, energy saving is about $11.96 \%$.
\end{abstract}

This is an open access article under the CC BY-SA license.

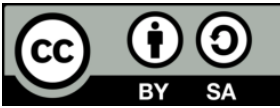

\section{Corresponding Author:}

An Thi Hoai Thu Anh

Department of Electrical Engineering

University of Transport and Communications

N0 3 Cau Giay, Lang Thuong Commune, Dong Da District, Hanoi, Vietnam

Email: htanh.ktd@utc.edu.vn

\section{INTRODUCTION}

Polluted air and heavy traffic jam are knotting issues related to transport in densely populated cities. Therefore, the urban electric train is one of the useful means of transportation to address these problems. However, its major disadvantage lies in consuming a large amount of electric energy in operation [1]-[4]. Therefore, reducing energy consumption and enhancing operation effectiveness of metro lines has long been one of hot studies worldwide. Many researchers, and engineers have tried their best to obtain remarkable achievements in theory and application, which has contributed in sustainable development of urban railway transportation. These theoretical and applied achievements include: recuperating regenerative braking energy by onboard/stationary energy storage systems [5]-[12], equipping the traction substations with reversible converters or active rectifiers so as to pump back the regenerative braking energy into utility source, as a result, all regenerated energy can be recuperated [13], [14], and optimizing scheduled timetables makes the regenerated energy among trains interchange easier [4], [15], [16], lowering energy losses in the power supply system, and in on-board traction equipment [17], applying optimal theory to seek the optimal speed 
profile to minimize operating energy [18]-[23], using interger linear programing determining optimal position for substations in order to reduce power loss [24]. Among above approaches, tracking the optimal speed curves to decrease energy consumption becomes one of the measures which does not need to invest in equipment or infrastructure of existing metro lines, so this one is most suitable for metro lines in Vietnam to have just been installed. The researchers of South Australia University in [25]-[29] outlined an energy-saving driving strategy for a train trip on a track with uphill and downhill gradients by designing control laws to calculate location of optimal switching points, and then determining the optimal speed profile but not to mention fixed running time. Baranov at al. [30] proposed a solution to minimize energy consumption and consider fixed trip time by supplementing Lagrange multiplier in objective function. Calculating to find the actual time equal to demand time is not easy, and repeated. Therefore, in this paper, pontryagin's maximum principle (PMP) has been presented to determine optimal speed profile for Cat Linh-Ha Dong metro line in Vietnam, and calculating fixed-running time by numerical analytical method thanks to maple software. Simulation results are conducted in two scenarios: running time of trains tracking the optimal speed profile is equal to that of original speed profile, and the other with running time of trains is longer than the original speed profile.

\section{TRAIN MODELING}

The continuous-space model of urban electric train operates in three motion regimes: Accelerating, coasting, braking is shown [31]-[33].

$$
\left\{\begin{array}{l}
\frac{d t}{d x}=\frac{1}{v} \\
v \frac{d v}{d x}=u_{t r} f_{t r}(v)-u_{b r} f_{b r}(v)-w_{0}(v)-f_{g r a d}(x)
\end{array}\right.
$$

Where $v, t, x, m$ represent train velocity $(m / s)$, operation time $(s)$, train position $(m)$, full load mass of train (tone), $u_{t r}, u_{b r}$ are defined traction and braking control variables of train, $f_{t r}, f_{b r}, f_{\text {grad }}$ are forces per unit mass; traction force applied at the wheels, braking force, mechanical force, gradient force acting on the train. where:

$$
f_{t r}=\frac{F_{t r}}{m} ; f_{b r}=\frac{F_{b r}}{m} ; f_{\text {grad }}=\frac{F_{g r a d}}{m}
$$

In which $F_{t r}, F_{b r}, W_{0}, F_{\text {grad }}$ are traction, braking, main resistance, gradient resistance forces, and these forces also have been differed from three motion phases for short inter-stations as shown in Figure 1.

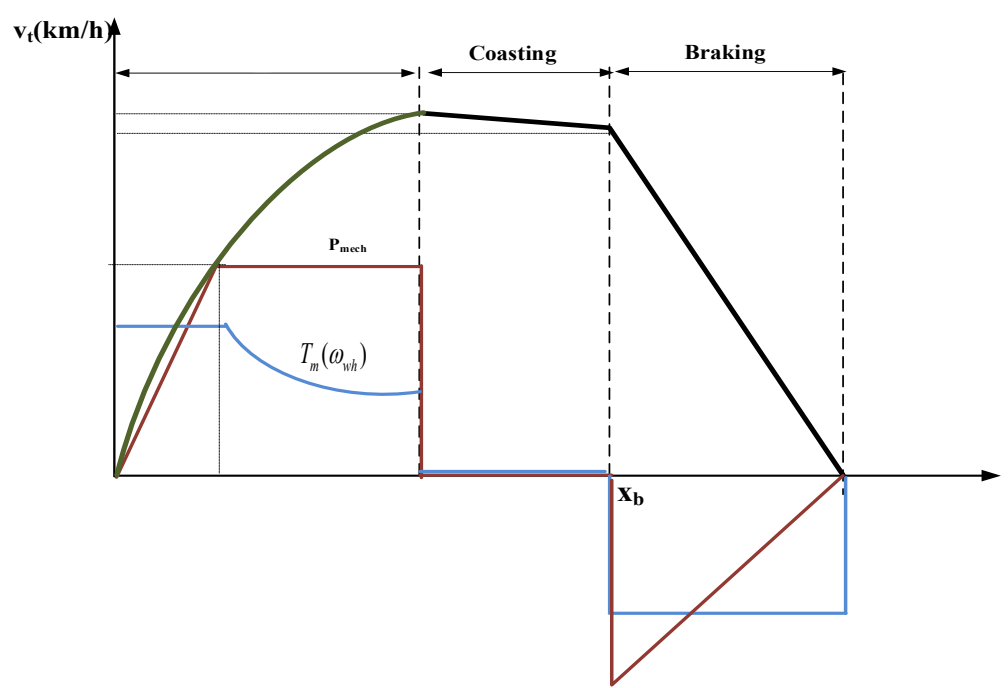

Figure 1. A typical speed profile with three motion phases for short inter-stations 
Manufacturers have given traction force $F_{t r}$, braking force $F_{b r}$ [34]. The traction force $F_{t r}$, braking force $F_{b r}$ are described as show in (2):

$$
\begin{aligned}
F_{t r} & =\left\{\begin{array}{cc}
13.2 & (0 \leq v \leq 32) \\
-2.5 \cdot 10^{-5} v^{3}+0.007 \cdot v^{2}-0.66 v+28.35 & (32<v \leq 80)
\end{array}\right. \\
F_{b r} & =\left\{\begin{array}{l}
14.7(0 \leq v \leq 65) \\
-0.254 v+31.21(65<v \leq 75) \\
-0.2027 v+27.36(75<v \leq 80)
\end{array}\right.
\end{aligned}
$$

Davis formula is used to calculate the basic resistance $w_{0}[35]$

$$
w_{0}=\frac{W_{0}}{m}=a+b v+c v^{2}
$$

In which $a, b, c$ are coefficients of train's resistance.

The gradient force $F_{\text {grad }}$ caused by slope of road:

$$
F_{\text {grad }}=m g \sin \alpha
$$

$g, \alpha$ are the gravity acceleration and the rail track slope respective.

\section{DETERMINATION OF FIXED TRIP TIME}

Ensuring the trip time complying with scheduled timetable when train operation tracks the optimal speed profile is the main goal of this section.

\subsection{Optimal speed curve determination based on PMP}

The optimal speed curve is determined thanks to seek the optimal switching points between the operation regimes, and detecting these switching points based on PMP. From the state (1), boundary conditions include (6), (7).

$$
\begin{aligned}
& v(0)=0, v(X)=0, t(0)=0 \\
& 0 \leq v(x) \leq V(x), 0 \leq t(X) \leq T, 0 \leq x \leq X
\end{aligned}
$$

Where $V(x)$ is the maximum allowable velocity, $X$ is the terminal of the train operation, $v(0), v(X)$ are the velocity at the beginning, at the end of the route, $T$ is duration of the trip is also given by the timetable.

The problem is how to lessen the train's consumption energy. The objective function is presented:

$$
J=\int_{0}^{X} u_{t r} f_{t r}(v) d x \rightarrow \min
$$

According to pontrygin's maximum principle, maximizing hamiltonian equation of the objective function $\mathrm{J}$ is going to find its optimal solutions. From (1) to (8), a Hamilton function is written as show in (9).

$$
H=-u_{t r} f_{t r}(v)+\frac{p_{1}}{v}+\frac{p_{2}}{v}\left(u_{t r} f_{t r}(v)-u_{b r} f_{b r}(v)-w_{0}(v)-f_{g r a d}(x)\right)
$$

Given, $p_{1}, p_{2}$ are co-state variables. Co-state variables are defined by (10):

$$
\frac{d p_{1}}{d x}=-\frac{\partial H}{\partial t}=0
$$




$$
\begin{aligned}
& \frac{d p_{2}}{d x}=-\frac{\partial H}{\partial v}=u_{t r} \frac{\partial f_{t r}}{\partial v}+p_{1} \frac{1}{v^{2}}+\frac{p_{2}}{v^{2}} \\
& {\left[u_{t r} f_{t r}(v)-u_{b r} f_{b r}(v)-w_{0}(v)-f_{g r a d}(x)\right]} \\
& -\frac{p_{2}}{v}\left[u_{t r} \frac{\partial f_{t r}}{\partial v}-u_{b r} \frac{\partial f_{b r}}{\partial v}-\frac{\partial w_{0}}{\partial v}\right]
\end{aligned}
$$

Define $p=\frac{p_{2}}{v}$, so $p \cdot v=p_{2}$. Therefore,

$$
\begin{aligned}
& \frac{d p_{2}}{d x}=\frac{d(p \cdot v)}{d x}=p \frac{d v}{d x}+v \frac{d p}{d x} \Rightarrow \frac{d p}{d x}=\frac{1}{v}\left(\frac{d p_{2}}{d x}-p \frac{d v}{d x}\right) \\
& \Rightarrow \frac{d p}{d x}=\frac{1}{v}\left(\frac{d p_{2}}{d x}-p \frac{d v}{d x}\right)
\end{aligned}
$$

Given

$$
\frac{d v}{d x}=\frac{u_{t r} f_{t r}(v)-u_{b r} f_{b r}(v)-w_{0}(v)-f_{g r a d}(x)}{v}
$$

Therefore, Hamiltonian function is reformed:

$$
H=(p-1) u_{t r} f_{t r}-p u_{b r} f_{b r}-p\left(w_{0}+f_{g r a d}\right)+\frac{p_{1}}{v}
$$

With the values of $u_{t r}$ and $u_{b r}$ related to $p$

$$
\left\{\begin{array} { c l l } 
{ u _ { t r } = 1 } & { \text { if } } & { p > 1 } \\
{ u _ { t r } \in ( 0 , 1 ) } & { \text { if } } & { p = 1 } \\
{ u _ { t r } = 0 } & { \text { if } } & { p < 1 }
\end{array} \text { and } \left\{\begin{array}{clc}
u_{b r}=0 & \text { if } & 0<p<1 \\
u_{b r} \in(0,1) & \text { if } & p=0 \\
u_{b r}=1 & \text { if } & p<0
\end{array}\right.\right.
$$

Optimal control laws are designed to maximize Hamiltonian function:

- $\quad$ Full power (FP): $u_{t r}=1, u_{b r}=0$ when $p>1$

- $\quad$ Partial power (PP): $u_{t r} \in[0,1], u_{b r}=0$ when $p=1$

- Coasting (C): $u_{t r}=0, u_{b r}=0$ when $0<p<1$

- $\quad$ Full braking (FB): $u_{t r}=0, u_{b r}=1$ when $p<0$

- $\quad$ Partial braking (PB): $u_{t r}=0, u_{b r} \in[0,1]$ when $p=0$

\subsection{Fixed trip time}

The trip time in every operation regime needs to be calculated so that the total running time of the whole line is abided by the train scheduled timetable exactly. Calculating the total running time is divided in to three phases.

\subsubsection{Accelerating phase}

Equation motion of the train in optimal traction mode:

$$
\frac{d v}{d t}=f_{t r}(v)-w_{0}(v)
$$

Using the variable dissociation method, the running time in accelerating phase is expressed as (18). 


$$
\begin{aligned}
& \frac{d v}{f_{t r}(v)-w_{0}(v)}=d t \rightarrow \int_{0}^{v_{h}} \frac{d v}{f_{t r}(v)-w_{0}(v)} \\
& =\int_{0}^{t_{a}} d t \rightarrow \int_{0}^{v_{h}} \frac{d v}{f_{t r}(v)-w_{0}(v)}=t_{a}
\end{aligned}
$$

Where: $f_{t r}$ is calculated as (2), from (18) the acceleration time may be employed (19):

$$
\begin{aligned}
& t_{a}=\int_{0}^{32} \frac{d v}{f_{t r}(v)-w_{0}(v)}+\int_{32}^{v_{h}} \frac{d v}{f_{t r}(v)-w_{0}(v)} \\
& =\int_{0}^{32} \frac{d v}{\frac{13.2}{247000}-\left(a+b v+c v^{2}\right)}+\int_{32}^{v_{h}} \frac{d v}{\left(-2.5 \cdot 10^{-5} v^{3}+0.007 \cdot v^{2}-0.66 v+28.35\right)-\left(a+b v+c v^{2}\right)} \\
& =-\left.10^{7} \frac{1}{\sqrt{10^{14} a c-25 \cdot 10^{12} b^{2}-5.34 \cdot 10^{9} c}} \arctan \left(250 \cdot 10^{-9} \frac{2 \cdot 10^{13}(2 c v+b)}{\sqrt{10^{14} a c-25 \cdot 10^{12} b^{2}-5.34 \cdot 10^{9} c}}\right)\right|_{0} ^{32}
\end{aligned}
$$

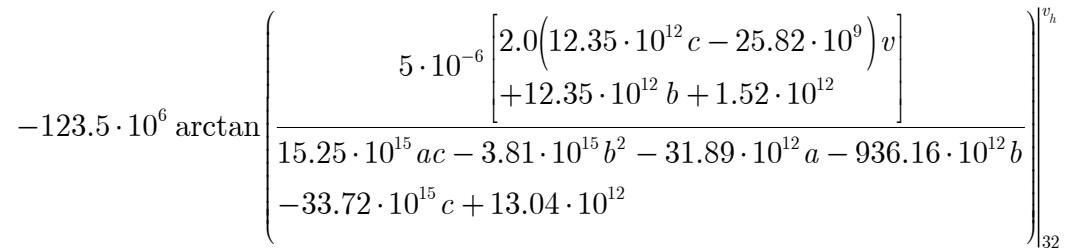

$$
\begin{aligned}
& \sqrt{15.25 \cdot 10^{15} a c-3.81 \cdot 10^{15} b^{2}-31.89 \cdot 10^{12} a-936.16 \cdot 10^{12} b-33.72 \cdot 10^{15} c+13.04 \cdot 10^{12}}
\end{aligned}
$$

Using the MAPLE software tool, the acceleration time as a function of velocity. Acceleration distance is calculated as (20):

$$
\text { From: } \begin{aligned}
\frac{d x}{d t}= & v \rightarrow d x=v d t=\frac{v d v}{f_{t r}(v)-w_{0}(v)} \rightarrow \int_{0}^{x_{a}} d x=\int_{0}^{v_{h}} \frac{v d v}{f_{t r}(v)-w_{0}(v)} \\
& \rightarrow x_{a}=\int_{0}^{v_{h}} \frac{v d v}{v_{a}(v)-w_{0}(v)} \rightarrow \int_{0}^{x_{a}} d x=\int_{0}^{v_{h}} \frac{v d v}{f_{t r}(v)-w_{0}(v)} \\
\rightarrow x_{a} & =\int_{0}^{v_{h}} \frac{v d v}{f_{t r}(v)-w_{0}(v)}
\end{aligned}
$$

\subsubsection{Coasting phase}

Motion equation of the train in optimal coasting mode:

$$
\frac{d v}{d t}=-w_{0}(v)
$$

Using the variable dissociation method, the running time in coasting phase obtains:

$$
\frac{d v}{-w_{0}(v)}=d t \rightarrow \int_{v_{h}}^{v_{b}} \frac{d v}{-w_{0}(v)}=\int_{t_{a}}^{t_{a}+t_{c}} d t \rightarrow t_{c}=\int_{v_{b}}^{v_{h}} \frac{d v}{a+b v+c v^{2}}=2 \frac{1}{\sqrt{4 a c-b^{2}}} \arctan \left(\frac{2 c v+b}{\sqrt{4 a c-b^{2}}}\right)
$$

In which braking velocity $v_{b}$ is given as follows [35], [36].

$$
\begin{aligned}
& v_{b}=\frac{\psi\left(v_{h}\right)}{\varphi^{\prime}\left(v_{h}\right)} \text { with } \varphi(v)=v \cdot w_{0}(v), \psi(v)=v^{2} \cdot w_{0}^{\prime}(v) \\
& \rightarrow v_{b}=\frac{v_{h}}{1+\frac{w_{0}\left(v_{h}\right)}{v_{h} w_{0}^{\prime}\left(v_{h}\right)}}=\frac{v_{h}}{1+\frac{a+v_{h}\left(b+c v_{h}\right)}{v_{h}\left(b+2 c v_{h}\right)}}
\end{aligned}
$$

Coasting distance is computed as (24): 
From: $\frac{d x}{d t}=v \rightarrow d x=v d t=\frac{v d v}{-w_{0}(v)} \rightarrow \int_{x_{a}}^{x_{a}+x_{c}}$
$d x=\int_{v_{h}}^{v_{b}} \frac{v d v}{-w_{0}(v)} \rightarrow x_{c}=\int_{v_{b}}^{v_{h}} \frac{v d v}{a+b v+c v^{2}}$

\subsubsection{Braking phase}

Motion equation of the train in optimal braking mode (25):

$$
\frac{d v}{d t}=-w_{0}(v)-f_{b r}(v)
$$

Using the variable dissociation method, the running time in braking phase is given by (26):

$$
\begin{aligned}
& \frac{d v}{-f_{b r}(v)-w_{0}(v)}=d t \rightarrow \int_{v_{b}}^{0} \frac{d v}{-f_{b r}(v)-w_{0}(v)} \\
& =\int_{t_{a}+t_{c}}^{t_{a}+t_{c}+t_{b}} d t \rightarrow \int_{0}^{v_{b}} \frac{d v}{f_{b r}(v)+w_{0}(v)}=t_{b}
\end{aligned}
$$

$F_{b r}$ is calculated as shown in (3)

From (4) the braking time can be written as (27).

$$
t_{b}=\int_{0}^{v_{b}} \frac{d v}{f_{b r \max }+\left(a+b v+c v^{2}\right)}=2 \frac{1}{\sqrt{4 a c-b^{2}+4 c f_{b r \max }}} \arctan \left(\frac{2 c v+b}{\sqrt{4 a c-b^{2}+4 c f_{b r \max }}}\right)
$$

The braking distance is calculated (28).

$$
\begin{aligned}
& \frac{d x}{d t}=v \rightarrow d x=v d t=\frac{v d v}{-f_{b r}(v)-w_{0}(v)} \rightarrow \int_{x_{a}+x_{c}}^{x_{a}+x_{c}+x_{b}} \\
& d x=\int_{v_{b}}^{0} \frac{v d v}{-f_{b r}(v)-w_{0}(v)} \rightarrow x_{b}=\int_{0}^{b_{b}} \frac{v d v}{f_{b r}(v)+w_{0}(v)}
\end{aligned}
$$

\section{RESULTS AND DISCUSSION}

The simulation parameters shown in Table 1, Table 2 collected from Cat Linh-Ha Dong metro line, Vietnam with 12 stations and $12.661 \mathrm{~km}$ long [34]. Simulation results carried out with two scenarios: running time complies with scheduled timetable, and running time is one second longer than scheduled timetable. The first scenario: The running time complies with scheduled timetable.

Table 1. Electric train parameters

\begin{tabular}{ccc}
\hline Parameters & Unit & Value \\
\hline Train grand-up & $2 \mathrm{M} 2 \mathrm{~T}$ & \\
Mass & $\mathrm{kg}$ & 246700 \\
Number of traction motors & & 08 \\
Max speed & $\mathrm{km} / \mathrm{h}$ & 80 \\
Base speed & $\mathrm{km} / \mathrm{h}$ & 40 \\
Max acceleration/braking rates & $\mathrm{m} / \mathrm{s}^{2}$ & $0.94 / 1$ \\
\hline
\end{tabular}

Table 2. Coefficients of basic resistance force

\begin{tabular}{cc}
\hline Parameters & Value \\
\hline$a$ & $1.19 \cdot 10^{-2}$ \\
$b$ & $2.56 \cdot 10^{-3}$ \\
$c$ & $1.54 \cdot 10^{-4}$ \\
\hline
\end{tabular}

The second scenario: The running time is one second longer than scheduled timetable. The trip time complied with scheduled timetable indicated in Figure 2, Table 3. Figure 3 showed optimal switching points 
change, so do optimal accelerating, coasting, braking distances considerability. Table 3 also demonstrated that the lowest saving energy is $3.33 \%$ while the highest saving energy is to $10.15 \%$; therefore, saving energy of the whole route is $8.7 \%$. In the second scenario, running time is one second longer than original time indicated in Figures 4, 5, and Table 4, but saving energy of the whole route is $11.96 \%$.

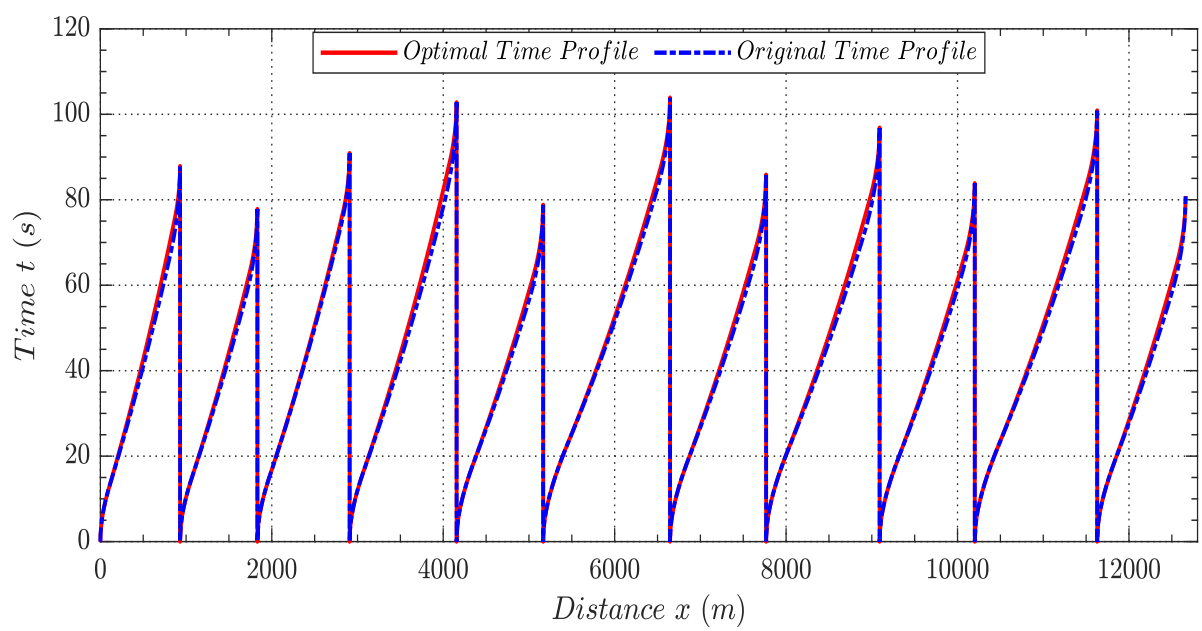

Figure 2. Responses of optimal time profile and original time profile

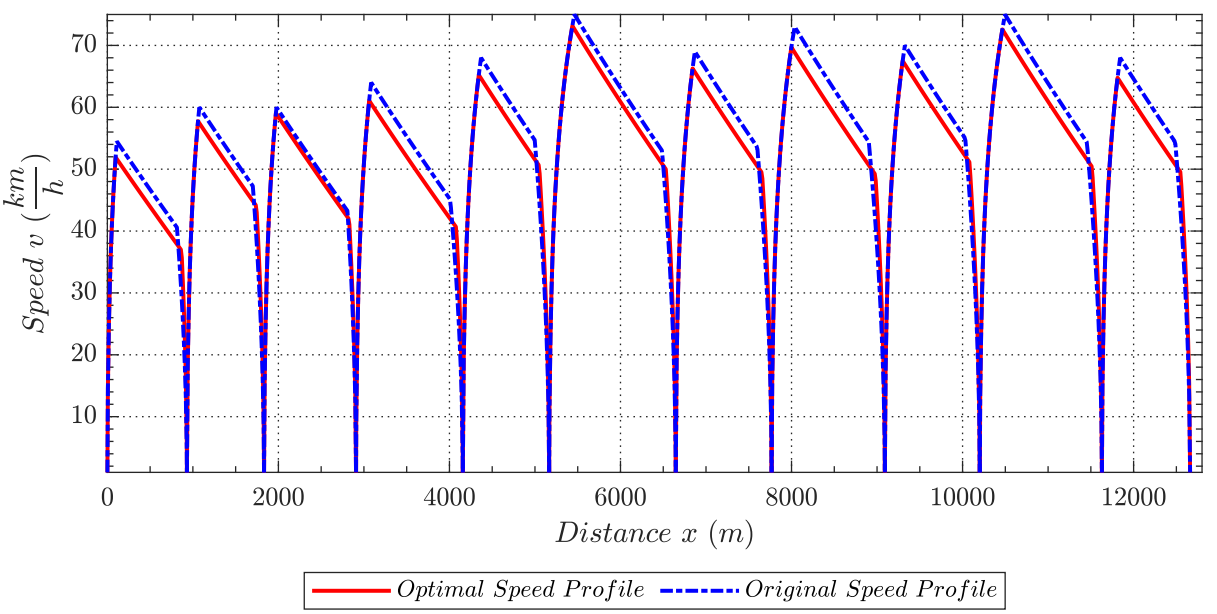

Figure 3. Responses of optimal velocity profile and original velocity profile

Table 3. Results of energy consumption with/without energy optimal strategy, and fixed trip time

\begin{tabular}{|c|c|c|c|c|c|}
\hline Stations & $\begin{array}{l}\text { Distance } \\
(\mathrm{m})\end{array}$ & $\begin{array}{l}\text { Trip time } \\
\text { (s) }\end{array}$ & $\begin{array}{c}\text { Actual energy } \\
\text { consumption }(\mathrm{kWh})\end{array}$ & $\begin{array}{c}\text { Optimal energy } \\
\text { consumption }(\mathrm{kWh})\end{array}$ & $\begin{array}{c}\text { Energy saving } \\
(\%)\end{array}$ \\
\hline Cat Linh-La Thanh & 931 & 88 & 8.31 & 7.50 & 9.75 \\
\hline La Thanh-Thai Ha & 902 & 78 & 10.20 & 9.40 & 7.84 \\
\hline Thai Ha-Lang & 1076 & 91 & 10.20 & 9.86 & 3.33 \\
\hline Lang- Thuong Dinh & 1248 & 103 & 11.73 & 10.60 & 9.63 \\
\hline Thuong Dinh- Ring Road 3 & 1010 & 79 & 13.41 & 12.23 & 8.80 \\
\hline Ring Road 3-Phung Khoang & 1480 & 104 & 16.75 & 15.82 & 5.55 \\
\hline Phung Khoang-Van Quan & 1121 & 86 & 13.85 & 12.66 & 8.59 \\
\hline Van Quan - Ha Dong & 1324 & 97 & 15.74 & 14.17 & 9.97 \\
\hline Ha Dong-La Khe & 1110 & 84 & 14.30 & 13.18 & 7.83 \\
\hline La Khe-Van Khe & 1428 & 101 & 16.75 & 15.53 & 7.28 \\
\hline Van Khe-Yen Nghia & 1032 & 81 & 13.40 & 12.04 & 10.15 \\
\hline Total energy consumption & & & 144.64 & 132.99 & 8.7 \\
\hline
\end{tabular}




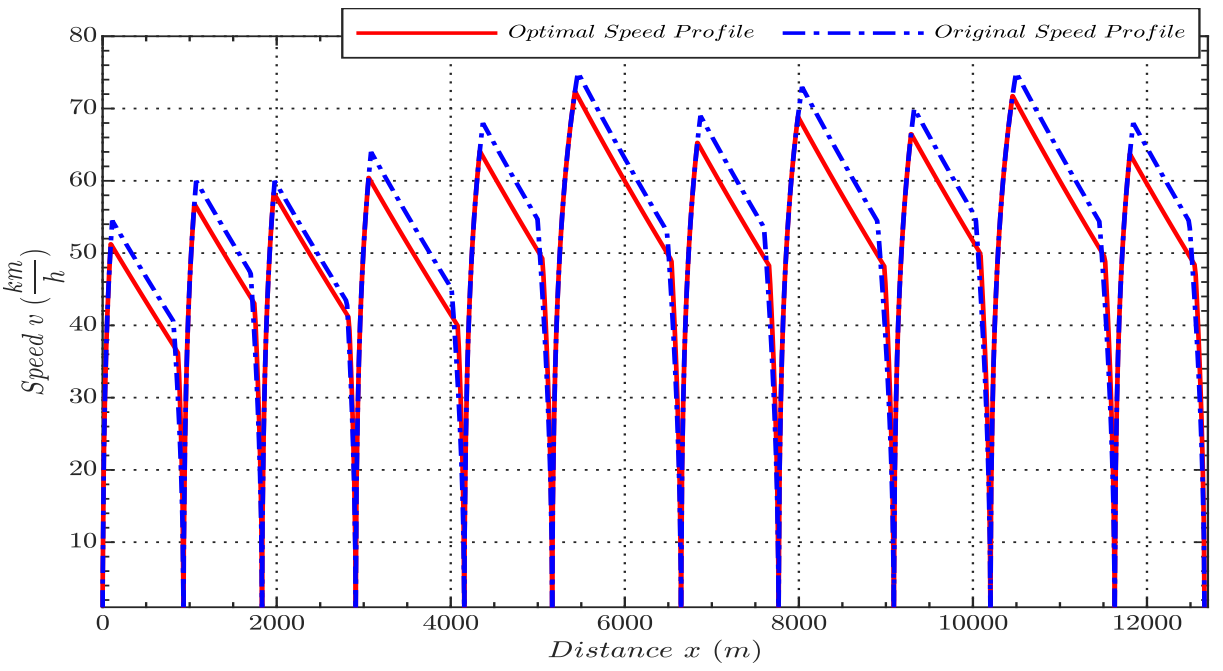

Figure 4. Responses of optimal velocity profile and original velocity profile without fixed trip time

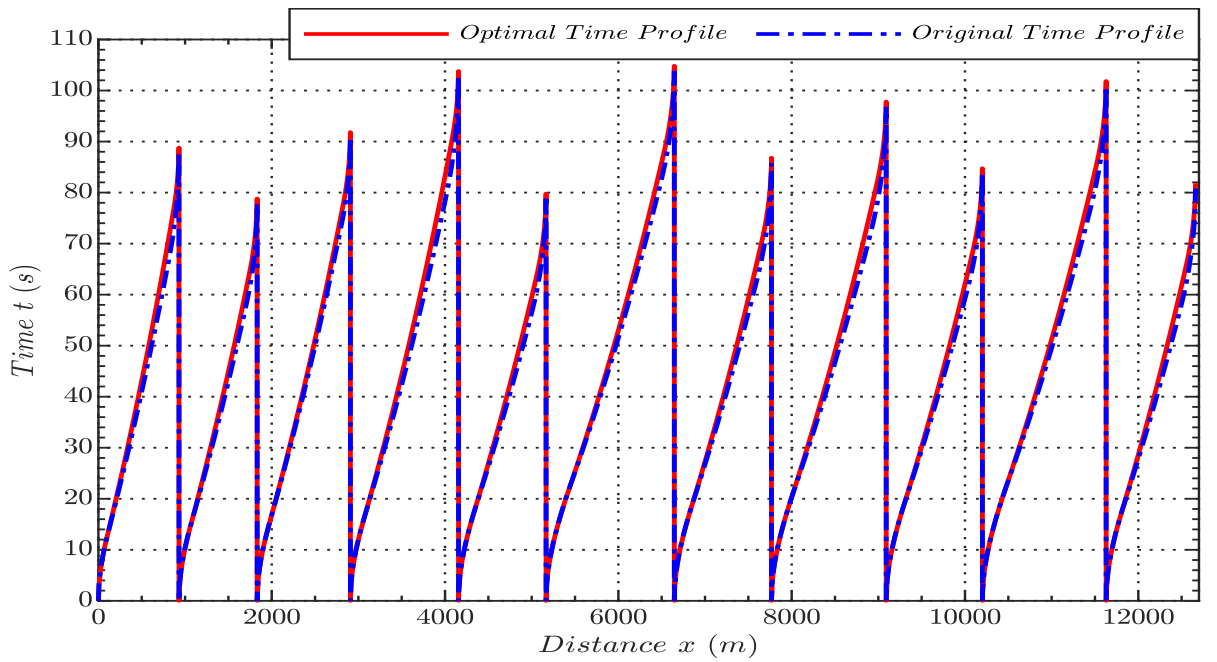

Figure 5. Responses of optimal time profile and original time profile without fixed trip time

Table 4. Results of a comparison of energy consumption with/without energy optimal strategy and non-fixed

\begin{tabular}{|c|c|c|c|c|c|c|}
\hline Stations & $\begin{array}{l}\text { Distance } \\
(\mathrm{m})\end{array}$ & $\begin{array}{l}\text { Original trip } \\
\text { time (s) }\end{array}$ & $\begin{array}{c}\text { Actual energy } \\
\text { consumption (kWh) }\end{array}$ & $\begin{array}{l}\text { Optimal trip } \\
\text { time (s) }\end{array}$ & $\begin{array}{c}\text { Optimal energy } \\
\text { consumption (kWh) }\end{array}$ & $\begin{array}{c}\text { Energy } \\
\text { saving (\%) }\end{array}$ \\
\hline Cat Linh-La Thanh & 931 & 88 & 8.31 & 88.81 & 7.31 & 13.68 \\
\hline La Thanh-Thai Ha & 902 & 78 & 10.20 & 78.83 & 9.08 & 12.33 \\
\hline Thai Ha-Lang & 1076 & 91 & 10.20 & 91.85 & 9.60 & 6.25 \\
\hline Lang- Thuong Dinh & 1248 & 103 & 11.73 & 103.82 & 10.37 & 13.11 \\
\hline $\begin{array}{c}\text { Thuong Dinh- Ring } \\
\text { Road } 3\end{array}$ & 1010 & 79 & 13.41 & 79.8 & 11.78 & 13.84 \\
\hline $\begin{array}{l}\text { Ring Road 3-Phung } \\
\text { Khoang }\end{array}$ & 1480 & 104 & 16.75 & 104.85 & 15.44 & 8.48 \\
\hline $\begin{array}{c}\text { Phung Khoang-Van } \\
\text { Quan }\end{array}$ & 1121 & 86 & 13.85 & 86.82 & 12.26 & 12.97 \\
\hline Van Quan - Ha Dong & 1324 & 97 & 15.74 & 97.83 & 13.80 & 14.06 \\
\hline Ha Dong-La Khe & 1110 & 84 & 14.30 & 84.77 & 12.77 & 11.98 \\
\hline La Khe-Van Khe & 1428 & 101 & 16.75 & 101.86 & 15.15 & 10.56 \\
\hline Van Khe-Yen Nghia & 1032 & 81 & 13.40 & 81.82 & 11.62 & 15.32 \\
\hline $\begin{array}{l}\text { Total energy } \\
\text { consumption }\end{array}$ & & & 144.64 & & 129.18 & 11.96 \\
\hline
\end{tabular}




\section{CONCLUSION}

Simulation results with data collected from Metro line Cat Linh-Ha Dong, Vietnam indicated that applying the numerical-analytical method to calculate running time equal to demand time is easy when using Pontryagin's maximum principle finds the optimal speed curve, and levels of energy saving $(8.7 \%$, and $11.96 \%)$. This research also has supported for designing the optimal speed profiles with the trip time suitable for operation stages of metro lines being in the technical design phase.

\section{REFERENCES}

[1] S. Shuai, T. Tang, and Y. Wang, "Evaluation of strategies to reducing traction energy consumption of metro systems using an optimal train control simulation model," Energies, vol. 9, no. 2, pp. 1-19, 2016, doi: 10.3390/en9020105.

[2] X. Yang, X. Li, B. Ning, and T. Tang, "A Survey on Energy-Efficient Train Operation for Urban Rail Transit," in IEEE Transactions on Intelligent Transportation Systems, vol. 17, no. 1, pp. 2-13, Jan. 2016, doi: 10.1109/TITS.2015.2447507.

[3] A. González-Gil, R. Palacin, and P. Batty, "Optimal energy management of urban rail systems: Key performance indicators," Energy conversion and management, vol.90, pp. 282-291, 2015, doi: 10.1016/j.enconman.2014.11.035.

[4] A. González-Gil, R. Palacin, P. Batty, and J. P. Powell, "A systems approach to reduce urban rail energy consumption," Energy Conversion and Management, vol. 80, pp. 509-524, 2014, doi: 10.1016/j.enconman.2014.01.060

[5] M. Steiner, M. Klohr, and S. Pagiela, "Energy storage system with ultracaps on board of railway vehicles," 2007 European Conference on Power Electronics and Applications, 2007, pp. 1-10, doi: 10.1109/EPE.2007.4417400.

[6] M. P. Schroeder, J. Yu, and D. Teumin, "Guiding the selection and application of wayside energy storage technologies for rail transit and electric utilities," No. TCRP Project J-6/Task 75. 2010.

[7] R. Barrero, X. Tackoen, and J. V. Mierlo, "Enhanced energy storage systems for improved on-board light rail vehicle efficiency," IEEE Vehicular Technology Magazine, vol. 3, pp. 26-36, 2008, doi: 10.1115/JRC2008-63054.

[8] L. Battistelli, F. Ciccarelli, D. Lauria, and D. Proto, "Optimal design of DC electrified railway stationary storage system," 2009 International Conference on Clean Electrical Power, 2009, pp. 739-745, doi: 10.1109/ICCEP.2009.5211971.

[9] D. Iannuzzi, F. Ciccarelli, and D. Lauria, "Stationary ultracapacitors storage device for improving energy saving and voltage profile of light transportation networks," Transportation Research Part C: Emerging Technologies, vol. 21.1, pp. 321-337, 2012.

[10] R. Teymourfar et al., "Stationary super-capacitor energy storage system to save regenerative braking energy in a metro line," Energy Conversion and Management, vol. 56, pp. 206-214, 2012, doi: 10.1016/j.trc.2011.11.002.

[11] M. Khodaparastan and A. Mohamed, "A study on super capacitor wayside connection for energy recuperation in electric rail systems," 2017 IEEE Power and Energy Society General Meeting, 2017, pp. 1-5, doi: 10.1109/PESGM.2017.8273915.

[12] D. Cornic, "Efficient recovery of braking energy through a reversible dc substation," Electrical Systems for Aircraft, Railway and Ship Propulsion, 2010, pp. 1-9, doi: 10.1109/ESARS.2010.5665264.

[13] H. Ibaiondo and A. Romo, "Kinetic energy recovery on railway systems with feedback to the grid," Proceedings of 14th International Power Electronics and Motion Control Conference EPE-PEMC 2010, 2010, pp. T9-94-T9-97, doi: 10.1109/EPEPEMC.2010.5606545.

[14] T. Albrecht, "Reducing power peaks and energy consumption in rail transit systems by simultaneous train running time control," WIT Transactions on State-of-the-art in Science and Engineering, vol. 39, 2010, doi: 10.2495/978-184564-498-7/01.

[15] A. Nasri, M. F. Moghadam, and H. Mokhtari, "Timetable optimization for maximum usage of regenerative energy of braking in electrical railway systems," SPEEDAM, 2010, pp. 1218-1221, doi: 10.1109/SPEEDAM.2010.5542099.

[16] M. Peña-Alcaraz et al., "Optimal underground timetable design based on power flow for maximizing the use of regenerative-braking energy," Proceedings of the Institution of Mechanical Engineers, Part F: Journal of Rail and Rapid Transit, vol. 226.4, pp. 397-408, 2012, doi: 10.1177/0954409711429411.

[17] C. Gong, S. Zhang, F. Zhang, J. Jiang, and X. Wang, "An integrated energy-efficient operation methodology for metro systems based on a real case of Shanghai metro line one," Energies, vol. 7.11, pp.7305-7329, 2014, doi: 10.3390/en7117305.

[18] M. Joy and S. Krishnakumar, "Optimal design of adaptive power scheduling using modified ant colony optimization algorithm," International Journal of Electrical and Computer Engineering (IJECE), vol. 10, no. 1, pp. 738-745, 2020, doi: 10.11591/ijece.v10i1.pp738-745.

[19] K. Sekaran et al., "An energy-efficient cluster head selection in wireless sensor network using grey wolf optimization algorithm," TELKOMNIKA Telecommunication, Computing, Electronics and Control, vol. 18, no. 6, pp. 2822-2833, 2020, doi: 10.12928/TELKOMNIKA.v18i6.15199.

[20] O. Ogunbiyi, O. Y. Ogundepo, I. S. Madagu, C. Thomas, and B. J. Olufeagba, "A progressive domain expansion method for solving optimal control problem," TELKOMNIKA Telecommunication, Computing, Electronics and Control, vol. 18, no. 4, pp. 2062-2069, 2020, doi: 10.12928/TELKOMNIKA.v18i4.15047. 
[21] M. Abdillah, H. Setiadi, and D. Sulistyo, "Improvement of voltage profile for large scale power system using soft computing approach," TELKOMNIKA Telecommunication, Computing, Electronics and Control, vol. 18, no. 1, pp. 376-384, 2020, doi: 10.12928/telkomnika.v18i1.13379.

[22] I. Abdou and M. Tkiouat, "Unit Commitment Problem in Electrical Power System: A Literature Review," International Journal of Electrical and Computer Engineering (IJECE), vol. 8, no. 3, pp. 1357-1372, 2018, doi: 10.11591/ijece.v8i3.pp1357-1372.

[23] A. T. H. T. Anh, N. V. Quyen, N. Hai, N. V. Lien, and P. Vu, "Speed profile optimization of an electrified train in cat linh-ha dong metro line based on pontryagin's maximum principle," International Journal of Electrical and Computer Engineering (IJECE), vol. 10, no. 1, pp. 233, 2020, doi: 10.11591/ijece.v10i1.pp233-242.

[24] T. V. Khoi and N. D. Khuong, "Optimal planning of substations on urban railway power supply systems using integer linear programming," Transport and Communications Science Journal, vol. 70, no. 4, pp. 264-278 2019.

[25] A. Albrecht, P. Howlett, P. Pudney, X. Vu, and P. Zhou, "The key principles of optimal train control-part 1: Formulation of the model, strategies of optimal type, evolutionary lines, location of optimal switching points," Transportation Research Part B: Methodological, vol. 94, pp. 482-508, 2014, doi: 10.1016/j.trb.2015.07.023.

[26] A. Albrecht, P. Howlett, P. Pudney, X. Vu, and P. Zhou, "The key principles of optimal train control-part 2: Existence of an optimal strategy, the local energy minimization principle, uniqueness, computational techniques," Transportation Research Part B: Methodological, vol. 94, pp. 509-538, 2014, doi: 10.1016/j.trb.2015.07.024.

[27] P. Howlett, P. J. Pudney, and X. Vu, "Local energy minimization in optimal train control," Automatica, vol. 45, no. 11, pp. 2692-2698, 2009, doi: 10.1016/j.automatica.2009.07.028.

[28] P. Howlett, "The optimal control of a train," Annals of Operations Research, vol. 98, no. 1, pp. 65-87, 2000, doi: 10.1023/A:1019235819716.

[29] A. R. Albrecht, P. G. Howlett, P. J. Pudney, and X. Vu, "Energy-efficiency train control: From local convexity to global optimization and uniqueness," Automatica, vol. 49, no. 10, pp. 3072-3078, 2013, doi: 10.1016/j.automatica.2013.07.008.

[30] L. A. Baranov, I. S. Meleshin, and L. M. Chin', "Optimal control of a subway train with regard to the criteria of minimum energy consumption," Russian Electrical Engineering, vol. 82, no. 8, pp. 9-14, 2011, doi: $10.3103 /$ S1068371211080049.

[31] D. D. Tuan and N. D. Toan, "Developing a program to calculate the unitresultant force of trains on Vietnam railways," Transport and Communications Science Journal, vol. 71, no. 8, pp. 907-923, 2020.

[32] N. V. Tiem, "Speed control for the train of urban railway using fuzzy-d controller," Transport and Communications Science Journal, vol. 71, no. 6, pp. 640-650, 2020.

[33] X. Sun, H. Lu and H. Dong, "Energy-Efficient Train Control by Multi-Train Dynamic Cooperation," in IEEE Transactions on Intelligent Transportation Systems, vol. 18, no. 11, pp. 3114-3121, Nov. 2017, doi: 10.1109/TITS.2017.2682270.

[34] N. T. M. Chau, "Hanoi Urban Railway Project Cat Linh-Ha Dong Line. Package 1: EPC Contact. Technical Design, Book 2: Traffic organization and operation management," Railway Project Management Unit, Vietnam Railway Administration, 2014.

[35] J. Yang, L. Jia, S. Lu, Y. Fu, and J. Ge, "Energy-efficient speed profile approximation: An optimal switching region-based approach with adaptive resolution," Energies, vol. 9, no. 10, 2016, doi: 10.3390/en9100762.

[36] N. T. Hai, "Evaluation of effect Pontryagin's Maximum Principle for optimal control train by criteria of energy save," 2010 International Symposium on Computer, Communication, Control and Automation (3CA), 2010, pp. 363-366, doi: 10.1109/3CA.2010.5533807.

\section{BIOGRAPHIES OF AUTHORS}

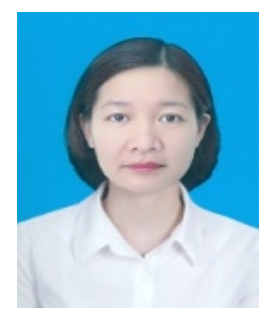

An Thi Hoai Thu Anh received her Engineer (1997), MSc (2002) degrees in Industrial Automation Engineering from Hanoi University of Science and Technology, and completed PhD degree in 2020 from University of Transport and Communications (UTC). Now, she is a lecturer of Faculty of Electrical and Electronic Engineering under University of Transport and Communications (UTC), Vietnam. Her current interests include Power Electronic Converters, Electric Motor Drive, Saving Energy solutions applied for Industry and Transportation

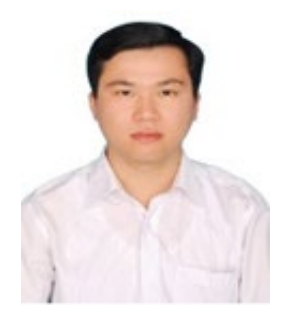

Nguyen Van Quyen received his Mechatronic Engineer (2009), MSc (2011) degrees in Engineering Mechanics from Hanoi University of Science and Technology (HUST). Now, he is a lecturer of Department Applied Mechanics of School of Mechanical Engineering under Hanoi University of Science and Technology, Vietnam. His current interests include Dynamics, Control and Optimization. 